\title{
INFLUENCE OF FORMULATION PARAMETERS ON DISSOLUTION RATE ENHANCEMENT OF ACYCLOVIR USING LIQUISOLID FORMULATION
}

\author{
KUBOTA MWAKA HAZEMBA, JIVAN JYOTI, SHEETU WADHWA*, SANANDA SOM, SOUVIK MOHANTA, \\ ANKIT KUMAR YADAV, BIMLESH KUMAR, VARUN GARG, DEEP SHIKHA SHARMA, RUBIYA KHURSHEED, \\ MONICA GULATI, SACHIN KUMAR SINGH
}

\author{
Department of Pharmacy, School of Pharmaceutical Sciences, Lovely Professional University, Phagwara, Punjab, India.
}

E-mail: sheetupharma@gmail.com/sheetu.21001@lpu.co.in

Received: 28 February 2018, Revised and Accepted: 16 March 2018

ABSTRACT

Objective: The objective of this research work is to explore the use of liquisolid technique in enhancement of acyclovir dissolution rate. This current study was planned to assess the impact of different formulation variables, such as non-volatile liquid type and concentrations of acyclovir on its dissolution rates profile.

Method: Acyclovir liquisolid tablets were prepared with Tween 60 (liquid vehicle), Microcrystalline cellulose PH 102 (acted as a carrier to turn liquid medication into free-flowing powder) and Syloid XDP (coating material). In vitro, drug dissolution rate of liquisolid formulations of acyclovir was performed and compared with pure acyclovir drug using USP dissolution apparatus (Type II) for 60 min at a paddle speed of 50 rpm and filled with $900 \mathrm{~mL}$ of distilled water.

Results: The dissolution study showed that $94.1 \%$ of the drug was released in 60 min of ratio 10 while only $66 \%$ of the pure drug acyclovir was released in $60 \mathrm{~min}$. Hence, present work concluded that the acyclovir dissolution rate profile has been improved with the formation of liquisolid formulations.

Conclusion: From the present study, it may be ratified that the drug dissolution rate of acyclovir has been improved with the utilization of liquisolid formulations approach.

Keywords: Acyclovir, Dissolution, Non-volatile liquid, Liquisolid tablets.

(C) 2018 The Authors. Published by Innovare Academic Sciences Pvt Ltd. This is an open access article under the CC BY license (http://creativecommons. org/licenses/by/4. 0/) DOI: http://dx.doi.org/10.22159/ajpcr.2018.v11s2.28537

\section{INTRODUCTION}

Nowadays, low solubility is the principle issue related with new drug moieties which should be overcome. The vast majority of the procedures that have prevailing with regard to conquering this issue are spray drying, micronization approach, $\beta$-cyclodextrins inclusion complexes, solid dispersions, and eutectic mixtures. However, among all, the feasible and financially savvy is liquisolid system. In liquisolid strategy, the drug is held in a solubilized state and molecularly dispersed in a liquid which helps to achieve the improved drug dissolution [1].

To overcome the bioavailability issue of poorly soluble drugs due to insufficient dissolution rate, numerous techniques are being utilized. Hydrophilic polymers as solubility enhancers are used in various approaches which perform through many ways in the development of various techniques such as cosolvency and inclusion complexes which provide numerous advantages toward formulation development. However, most of the time, during storage, these techniques show stability issues, and low industrial viability and are not commercially successful. Moreover, these techniques suffered with limitations such as hygroscopic and sticky mass which lead to poor flow of powders [2].

Liquisolid technology emerged as a new drug delivery system, differentiated due to its features and potential to deliver numerous drugs. These systems have drawn the attention of pharmaceutics scientists and scholars in the area of poorly soluble drugs for their solubility enhancement and controlled dissolution profile as per the formulation requisite [2]. This technology is patented by Spireas et al., in 1999, and is a simple process of physical mixing with selected excipients which turns it into a free-flowing, dry powder. The main formulation components of liquisolid systems are non-volatile liquid vehicle, a carrier, and a coating material. Moreover, as per the objectives and need of the study, sometimes other excipients such as disintegrants or superdisintegrants are used [3-5]

One of the anticipated mechanisms for the enhance the dissolution rate of the drug from the liquisolid compact mass is the wettability of the latter in the dissolution media. The component that helps in the wetting of drug particles in liquisolid system is the non-volatile solvent [6]. These solvent systems reduce the interfacial tension which was exist between the tablet surface and selected dissolution medium which results in increase effective surface area and wettability for dissolution [7]. Due to this fact, these liquisolid compacts show improved dissolution profile and enhanced bioavailability of poorly soluble drugs. The release of drug from these liquisolid compacts is mainly depends on few parameters, such as drug characteristics, type of carrier, and the type of liquid vehicle used in the formulation. Therefore, these should be optimized, and its effect on dissolution rate should be evaluated $[8,9]$

The main components of liquisolid systems are carrier material, coating material, non-volatile solvent, and disintegrant. Carrier material such as various grades of sorbitol, cellulose, lactose, and starch holds sufficient adsorption property [10]. Coating materials are highly adsorptive and usually in very fine particle size range. These are various grades of colloidal silica such as Syloid 
XDP, Syloid 244FP, Cab-0-Sil, and Aerosil 200. Non-volatile liquids such as polysorbates, fixed oils, liquid polyethylene glycols (PEG), propylene glycol, glycerin, $\mathrm{N}$, and $\mathrm{N}$-dimethylacetamide in which drug should be dissolved, were selected. The type and concentration of disintegrant or super-disintegrant are mainly based on the objective of the study. 5\% of disintegrant is mostly used in the formulations. For example, Sodium starch glycolate is the most commonly used disintegrant $[5,10]$.

Acyclovir, an antivirus drug is used to treat virus infections caused by herpes zoster and herpes simplex. However, acyclovir shows limited therapeutic potential due to its low oral bioavailability this is due to the fact that it has inadequate water solubility as well as low permeability [11].

Existing treatment options available for acyclovir includes oral, parenteral, and topical therapy. Among these routes, topical treatment is not much effective due to the low acyclovir permeability in the skin cells. While oral route is the most effective, appropriate and patientcompliant as compared to others but previous reports exhibited low and variable oral bioavailability of acyclovir and systemic adverse effects due to frequent oral dose administration [11].

Therefore, there is a need for advancement in the oral delivery of acyclovir which will prevent its systemic adverse effect and provide optimum drug concentration [11].

\section{MATERIALS AND METHODS}

\section{Materials}

Acyclovir API was procured from M/s Ind-Swift Laboratories, India. Tween 80, Tween 60, and Lactose were purchased from M/s SD Fine Chemicals Ltd., Mumbai, India. PEG 400 was obtained from M/s HiMedia Laboratories Pvt. Ltd, Mumbai, India. Microcrystalline cellulose (MCC) PH 102 was gifted by Colorcon Pvt. Ltd, Mumbai. Syloid XDP was gifted by Grace Materials Technologies, Discovery Sciences, Mumbai, India. All other chemicals, solvents, and reagents used were of analytical grade. Dissolution apparatus type II (Lab India, DS-8000, Mumbai, India), and Double beam ultraviolet (UV)-visible spectrophotometer (UV 1800) from Shimadzu Japan were used.

\section{Methods}

\section{Solubility determination}

Solubility studies were carried out in the different non-volatile solvent system. It helps in selection of suitable liquid vehicle for preparation of liquisolid compacts. Three different non-volatile solvents, i.e. PEG 400, Tween 60 , and Tween 80 are selected. Then, saturated drug solutions were prepared by distributing acyclovir (50 $\mathrm{mg}$ ) equally to a test tube containing $5 \mathrm{~mL}$ of PEG 400, Tween 80 , and Tween 60 separately. These tubes were then put in bath sonicator for $48 \mathrm{~h}$ for the process of sonication. The solutions were taken after $48 \mathrm{~h}$, and suitable dilutions were made $(1000,100$, and $10 \mathrm{ppm})$ using distilled water. The samples were diluted, filtered using $0.45 \mu \mathrm{m}$ Millipore filter and absorbance was noted in triplicate using UV/visible spectrophotometer at a wavelength of $255 \mathrm{~nm}$.

\section{Loading factor (Lf) of drug}

To turn the liquid medication into free-flowing powder one carrier - MCC PH102 and one coating agent - Syloid XDP was used. Hence, in $0.4 \mathrm{~mL}$ of liquid medication, weighed quantity of carrier $(400 \mathrm{mg})$ and drug $(50 \mathrm{mg}$ ) was added until a good flow of powder was achieved and in $0.8 \mathrm{~mL}$ of liquid medication, weighed quantity of coating agent (800 mg) and drug (100 mg) was added until good flow of powders of different ratios, namely 10,20 , and 30 were obtained. The Lf of the drug are useful parameter which helps in determination of carrier and coating materials amount in each formulation [12]. Therefore, the Lf of the batches containing Syloid XDP were calculated as per the formula given below in equation (1):

The formula is $\mathrm{Lf}=\mathrm{W} / \mathrm{C}$
In equation (1), $\mathrm{W}$ is the weight of the liquid medication in grams ( $\mathrm{g}$ ), and $\mathrm{C}$ is the weight of the carrier used.

\section{Drug content determination in liquisolid powder sample}

Acyclovir amount in the sample (dried) was estimated by dissolving liquisolid compact sample (e.g., containing acyclovir, Syloid XDP, and MCC PH 102) about $5 \mathrm{mg}$ in distilled water $(10 \mathrm{~mL})$, and then sonicated for $30 \mathrm{~min}$. Subsequently, the sample was filtered, and its absorbance reading (in triplicate) was noted using UV/visible Spectrophotometer at a wavelength of $255 \mathrm{~nm}$ [5].

\section{Flow properties - liquisolid powders}

Angle of repose

Angle of repose can be calculated with the help of a funnel placed on a tripod stand. This method is used to determine the frictional forces present in loose powder. The angle of repose is the maximum angle which is possible between the surface of a powder pile and the horizontal plane [4,13-15]. The formula for calculation of angle of repose is given below in equation (2).

$\operatorname{Tan} \theta=\mathrm{h} / \mathrm{r}$

(In equation 2, $\mathrm{h}$ is the height of powder conical pile, and $\mathrm{r}$ is the radius of the conical pile base).

\section{Bulk density}

Bulk density expressed in grams per milliliter $(\mathrm{g} / \mathrm{mL})$ is the weight of powder divided by its bulk volume [4,15]. The equation (3) for determining bulk density $(\rho b)$ is:

$\rho b=M / V b$

(In equation 3, $\rho b$ is Bulk density, $\mathrm{M}$ is mass of a sample in grams, and $\mathrm{Vb}$ is Bulk volume in $\mathrm{cm}^{3}$ )

Tapped density

Tapped density can be defined as the mass of blend in the measuring cylinder divided by its tapped volume [4,15]. The equation (4) for determining tapped density $(\rho \mathrm{t})$ is:

$\rho \mathrm{t}=\mathrm{M} / \mathrm{Vt}$

In equation 4 , $\rho t$ is Tapped density, $\mathrm{M}$ is mass of blend (g), and Vt is Tapped volume $\left(\mathrm{cm}^{3}\right)$.

\section{Moisture content}

Moisture content is a test that is taken to ensure the removal of all the moisture present in the liquisolid powder. It is done by putting the powder in Petri plates and placing them in an autoclave then checking their moisture content by weighing at different time intervals, i.e., after every 15-30 min $[4,15]$. The formula of moisture content is shown in equation (5):

Moisture content $(\%)=\mathrm{w}_{2}-\mathrm{w}_{3} / \mathrm{w}_{2}-\mathrm{w}_{1} \times 100$

In equation (5), $w_{1}$ is the weight of empty Petri plates, $w_{2}$ is the weight of Petri plate with sample, and $\mathrm{w}_{3}$ is the weight of Petri plate with sample after drying.

Product yield

Product yield or percentage yield is the product amount which is calculated from limiting reactant. Limiting reactant is that reactant in a chemical reaction which is going to limits the amount of final formed product. The practical yield is the actual amount that is produced when a reaction is carried out [4]. The difference between the practical yield and theoretical yield (gram or mole) and actual yield (gram or mole) can be calculated from the formula given in equation (6): 
Product yield $=\frac{\text { Practical yield }}{\text { Theoretical yield }} \times 100$

\section{Preparation of acyclovir liquisolid tablet}

Acyclovir liquisolid compacts were prepared by dispersed in Tween 60 which was used as the liquid vehicle to prepare the liquid medication [4]. The latter was added into the mixture of carrier-coating materials with continuous stirring which was compressed into a liquisolid tablet using tablet machine manually. The acyclovir liquisolid tablets prepared and are compared with pure acyclovir tablets. Different formulation attributes affecting the liquisolid compact tablets such as carrier-type, different Lf were taken into account during preparation of liquisolid tablets $[15,16]$.

\section{Dissolution studies of acyclovir}

In vitro, dissolution studies were performed on USP Dissolution Test Apparatus Type II (Lab India, DS-8000, Mumbai, India) for acyclovir liquisolid tablets and compared with pure acyclovir conventional tablet $[17,18]$. The amount of acyclovir release with time for 60 min was determined using distilled water $(900 \mathrm{~mL})$ as medium maintained at $37 \pm 0.5^{\circ} \mathrm{C}$ at a paddle speed of $50 \mathrm{rpm} .10 \mathrm{~mL}$ aliquots were withdrawn from the dissolution medium at predetermined time intervals of 5,10 , $15,30,45$, and $60 \mathrm{~min}$, respectively, and the medium was replaced with $10 \mathrm{~mL}$ of distilled water to maintain the sink condition. The aliquots were withdrawn, filtered through membrane filter $(0.45 \mu \mathrm{m})$ and analyzed in triplicate using UV/visible spectrophotometer at $255 \mathrm{~nm}[4,15,19]$.

For each formulation, drug release (\%) is calculated using the following formula in equation (7):

Drug release $(\%)=\frac{\text { Sample absorbance }}{\text { Standard absorbance }} \times \frac{\text { Standard dilution }}{\text { Sample dilution }}$

\section{RESULTS AND DISCUSSION}

Standard plot of acyclovir was prepared using distilled water as a solvent. A range of $2-10 \mathrm{mcg} / \mathrm{mL}$ acyclovir dilutions were prepared, and absorbance was noted at the wavelength of $255 \mathrm{~nm}$ using a UVvisible spectrophotometer, as shown in Fig. 1.

Solubility studies demonstrate that the drug acyclovir has revealed highest solubility in Tween 60 (i.e., $31.65 \%$ ) as compared to PEG400 and Tween 80 (Table 1). Hence, Tween 60 was selected as the better solvent vehicle for preparation of liquid medication [4].

Previous literature suggested that additives improve the flow properties and compatibility of liquisolid formulations. Lf (Table 2) was calculated. From Table 2, it was concluded that the liquisolid sample of ratio 10 has the highest Lf.

The absorbance for pure drug and liquisolid powder of coating agent only was observed at $255 \mathrm{~nm}$, and the results are shown in Table 3. From the absorbance reading, the acyclovir content in liquisolid tablet was found to be $77.44 \%$ [4].

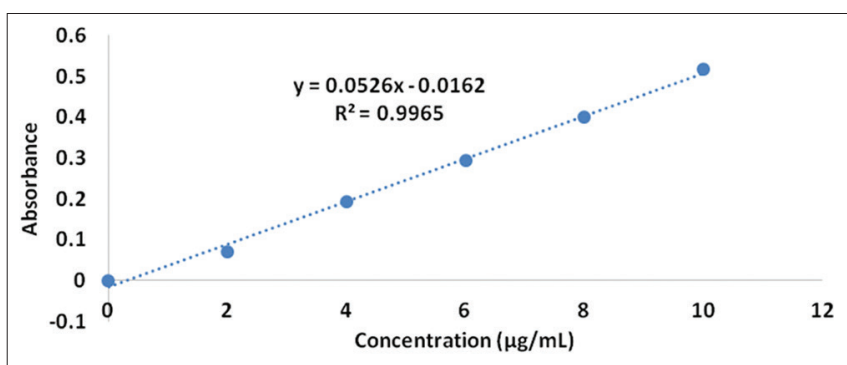

Fig. 1: Standard curve of acyclovir in distilled water at $255 \mathrm{~nm}$
The flow properties, i.e., angle of repose, bulk density, and tapped density are calculated and reported in Tables 4 and 5, respectively. In Table 5, the highest bulk density was seen in liquisolid powder of ratio 30 and the highest tapped density in the liquisolid sample with coating agent only [4]

Table 1: Solubility studies of acyclovir in non-volatile liquid vehicle

\begin{tabular}{llll}
\hline S. No & Non-volatile liquid vehicle & Ppm & Solubility (\%) \\
\hline 1 & PEG 400 & 100 & 24.5 \\
& & 10 & 10.8 \\
2 & Tween 60 & 100 & 31.65 \\
& & 10 & 18.5 \\
3 & Tween 80 & 100 & 26.5 \\
& & 10 & 17.8 \\
\hline
\end{tabular}

PEG: Polyethylene glycols

Table 2: Lf of different liquisolid ratios

\begin{tabular}{lll}
\hline Liquisolid sample & \multicolumn{2}{l}{ Lf $(\mathbf{W} / \mathbf{C})$} \\
\cline { 2 - 3 } & In grams & In $\boldsymbol{\mu L}$ \\
\hline Liquisolid sample with coating agent only & 0.4 & 400 \\
Liquisolid sample of ratio 10 (coating+carrier) & 1.68 & 1680 \\
Liquisolid sample of ratio 20 (coating+carrier) & 1.64 & 1640 \\
Liquisolid sample of ratio 30 (coating+carrier) & 1.63 & 1630 \\
\hline
\end{tabular}

Lf: Loading factor

Table 3: Determination of drug content in liquisolid powder sample

\begin{tabular}{ll}
\hline Sample & Absorbance (nm) \\
\hline Pure drug & 3.222 \\
Liquisolid powder & 2.495 \\
Actual drug content (\%) in liquisolid powder & 77.44 \\
\hline
\end{tabular}

Table 4: Angle of repose of liquisolid powders (Data in triplicate)

\begin{tabular}{|c|c|}
\hline \multicolumn{2}{|c|}{$\begin{array}{l}\text { 1. Liquisolid powder with coating agent only: } \\
\text { 1. } \mathrm{h}_{1}=0.5 \mathrm{~cm} \mathrm{r} \mathrm{r}_{1}=3.1 \mathrm{~cm} \\
\text { 2. } \mathrm{h}_{2}=0.4 \mathrm{~cm} \mathrm{r} r_{2}=3.6 \mathrm{~cm} \\
\text { 3. } \mathrm{h}_{3}=0.6 \mathrm{~cm} \mathrm{r} \mathrm{r}_{3}=4.0 \mathrm{~cm}\end{array}$} \\
\hline \multicolumn{2}{|c|}{ Average, height $(\mathrm{h})=0.5 \mathrm{~cm}$, radius $(\mathrm{r})=3.6 \mathrm{~cm}$} \\
\hline \multicolumn{2}{|c|}{$\begin{array}{l}\text { 2. Liquisolid formulation having carrier to coating ratio } 10 \text { : } \\
\begin{array}{l}\text { 1. } \mathrm{h}_{1}=0.9 \mathrm{~cm} \mathrm{r}_{1}=4.2 \mathrm{~cm} \\
\text { 2. } \mathrm{h}_{2}=1 \mathrm{~cm} \mathrm{r} \mathrm{r}_{2}=3.8 \mathrm{~cm} \\
\text { 3. } \mathrm{h}_{3}=1 \mathrm{~cm} \mathrm{r} \mathrm{r}_{3}=4 \mathrm{~cm}\end{array}\end{array}$} \\
\hline \multicolumn{2}{|c|}{ Average, height $(\mathrm{h})=0.96 \mathrm{~cm}$, radius $(\mathrm{r})=4 \mathrm{~cm}$} \\
\hline $\begin{array}{l}\text { 3. Liquisolid of having ca } \\
\text { 1. } \mathrm{h}_{1}=1 \mathrm{~cm} \mathrm{r}_{1}=3.9 \mathrm{~cm} \\
\text { 2. } \mathrm{h}_{2}=0.8 \mathrm{~cm} \mathrm{r}_{2}=4.2 \mathrm{~cm} \\
\text { 3. } \mathrm{h}_{3}=1 \mathrm{~cm} \mathrm{r}_{3}=3.7 \mathrm{~cm}\end{array}$ & ing ratio 20: \\
\hline \multicolumn{2}{|c|}{ Average, height $(\mathrm{h})=0.93 \mathrm{~cm}$, radius $(\mathrm{r})=3.9 \mathrm{~cm}$} \\
\hline \multicolumn{2}{|c|}{ 4. Liquisolid of having carrier to coating ratio 30 : } \\
\hline \multicolumn{2}{|c|}{ 1. $\mathrm{h}_{1}=1 \mathrm{~cm} \mathrm{r}_{1}=3.6 \mathrm{~cm}$} \\
\hline \multicolumn{2}{|l|}{ 2. $\mathrm{h}_{2}=1.2 \mathrm{~cm} \mathrm{r}_{2}=3.8 \mathrm{~cm}$} \\
\hline \multicolumn{2}{|c|}{ Average, height $(\mathrm{h})=1.13 \mathrm{~cm}$, radius $(\mathrm{r})=3.67 \mathrm{~cm}$} \\
\hline Liquisolid sample & Angle of repose $\left(^{\circ}\right)$ \\
\hline With coating agent only & 7.9 \\
\hline With ratio 10 & 13.5 \\
\hline With ratio 20 & 13.41 \\
\hline With ratio 30 & 17.11 \\
\hline
\end{tabular}


Table 5: Powder flow properties of acyclovir liquisolid tablets

\begin{tabular}{lll}
\hline Acyclovir liquisolid sample & Bulk density & Tapped density after 100 tappings \\
\hline Powder with coating agent only & $0.75 / 1.6=0.47$ & $0.75 / 1.2=0.63$ \\
Ratio 10 (carrier+coating agent) & $2.07 / 4.5=0.46$ & $2.07 / 3.4=0.61$ \\
Ratio 20 (carrier+coating agent) & $2.08 / 4.6=0.45$ & $2.08 / 3.5=0.59$ \\
Ratio 30 (carrier+coating agent) & $1.91 / 4=0.48$ & $1.91 / 3.1=0.62$ \\
\hline
\end{tabular}

Table 6: Moisture content of liquisolid samples

\begin{tabular}{|c|c|c|c|c|}
\hline Liquisolid sample & W1 & W2 & w3 & Quotient \\
\hline $\begin{array}{l}\text { Powder with coating agent } \\
\text { only }\end{array}$ & 37.30 & 38.05 & 35.50 & 3.4 \\
\hline Ratio 10 & 26.89 & 28.95 & 24.86 & 1.99 \\
\hline Ratio 20 & 31.50 & 33.58 & 30.50 & 1.48 \\
\hline Ratio 30 & 33.70 & 35.58 & 32.60 & 1.59 \\
\hline
\end{tabular}

Table 7: Product yield

\begin{tabular}{llll}
\hline Liquisolid sample & $\begin{array}{l}\text { Practical } \\
\text { yield }\end{array}$ & $\begin{array}{l}\text { Theoretical } \\
\text { yield }\end{array}$ & $\begin{array}{l}\text { Product } \\
\text { yield (\%) }\end{array}$ \\
\hline $\begin{array}{l}\text { Powder with } \\
\text { coating agent only }\end{array}$ & 0.71 & 0.85 & 83.52 \\
Ratio 10 & 1.94 & 1.78 & 108.98 \\
Ratio 20 & 1.94 & 1.74 & 111.49 \\
Ratio 30 & 1.77 & 1.7266 & 102.51 \\
\hline
\end{tabular}

Table 6 depicts that the liquisolid sample with the coating agent only had the highest amount of moisture content loss [15]. Among the various carrier to coating ratios used, the liquisolid powders having lowest carrier to coating ratio (i.e., $R=10$ ) showed the lowest angle of repose value.

Table 7 shows that the highest product yield was seen in liquisolid powder of ratio 20 .

The dissolution results of unprocessed acyclovir and its liquisolid formulations prepared by varying the carrier to coating ratio are shown in Fig. 2. The results clearly indicated that the dissolution profile of drug present in liquisolid formulations got significantly increased $(\mathrm{p}<0.05)$ as that unprocessed drug. It was observed that only $66 \%$ of drug got released from the unprocessed powder in $60 \mathrm{~min}$, whereas, more than $80 \%$ drug got released within $5 \mathrm{~min}$ from all the liquisolid formulations. Such observations clearly revealed that acyclovir got completely dissolved in tween-80 and remain adsorbed in solution state in the matrix of carrier and coating material [19]. Once they were introduced in the dissolution medium, the homogeneous solution of tween- 80 and drug got completely miscible with the medium. Among the various ratios, the liquisolid formulations having $\mathrm{R}$ equal to 10 showed the higher extent of drug release. This could be probably due to that fact that Syloid XDP is amorphous silica and has higher surface area as that of MCC PH 102. In lower ratio, the amount of Syloid XDP was more than MCC PH 102 which would have enhanced the wettability of formulation in the medium $[20,21]$.

\section{CONCLUSION}

This current study provides evidence that due to the liquisolid technique now it is possible to increase the dissolution of poorly soluble drug. The liquisolid tablets of acyclovir exhibit a remarkably improved dissolution rate in comparison with acyclovir plain tablet. Results of dissolution study showed greater dissolution rate of acyclovir from liquisolid compacts. The results are affected by changing the ratio of the carrier to coating material.

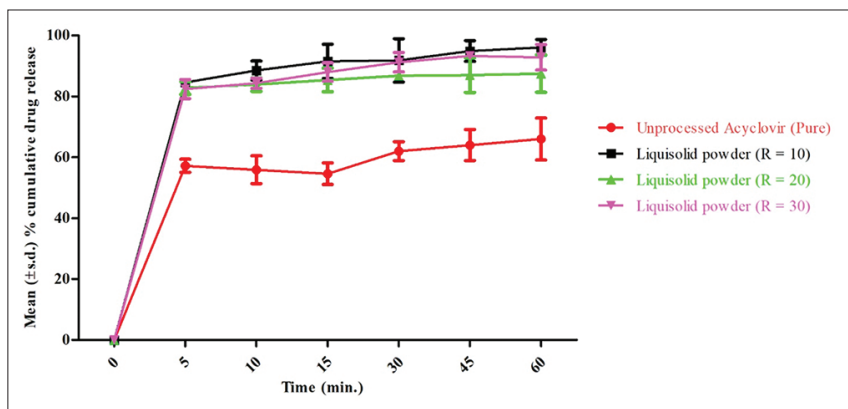

Fig. 2: Dissolution profile of acyclovir liquisolid compacts and pure acyclovir

\section{REFERENCES}

1. Kaur M, Bala R, Arora S. Liquisolid technology: A review. An Int J Adv Pharm Sci 2013:4:1-5.

2. Javadzadeh Y, Jafari-Navimipour B, Nokhodchi A. Liquisolid technique for dissolution rate enhancement of a high dose water-insoluble drug (carbamazepine). Int J Pharm 2007;341:26-34.

3. Spireas S, Bolton SM, Inventors; Spireas, Spiridon, Bolton, Sanford M., Assignee. Liquisolid Systems and Methods of Preparing Same. United States Patent US 5,968,550; 1999.

4. Singh SK, Srinivasan KK, Gowthamarajan K, Prakash D, Gaikwad NB, Singare DS, et al. Influence of formulation parameters on dissolution rate enhancement of glyburide using liquisolid technique. Drug Dev Ind Pharm 2012;38:961-70.

5. Sharma A, Jain CP. Techniques to enhance solubility of poorly soluble drugs: A review. J Global Pharm Technol 2010;2;18-28.

6. Patil U, Mudavath H, Patil S, Jadatkar K, Kumar G, Patel S. Liquisolid compact: A review. Int J Pharm Res Dev 2012;4:151-7.

7. Rao AS, Aparna TN. Liquisolid technology: An overview. Int J Res Pharm Biomed Sci 2011;2:409.

8. Chandel P, Kumari R, Kapoor A. Liquisolid technique: An approach for enhancement of solubility. J Drug Deliv Ther 2013;3:131-7.

9. Nagabandi VK, Ramarao T, Jayaveera KN. Liquisolid compacts: A novel approach to enhance bioavailability of poorly soluble drugs. Int J Pharm Biol Sci 2011;1:89-102.

10. Rajesh K, Rajalakshmi R, Umamaheswari J, Kumar CA. Liquisolid technique a novel approach to enhance solubility and bioavailability. Int J Biopharm 2011;2:8-13.

11. Nair AB, Attimarad M, Al-Dhubiab BE, Wadhwa J, Harsha S, Ahmed M. Enhanced oral bioavailability of acyclovir by inclusion complex using hydroxypropyl- $\beta$-cyclodextrin. Drug Deliv 2014;21:540-7.

12. Hentzschel CM, Sakmann A, Leopold CS. Suitability of various excipients as carrier and coating materials for liquisolid compacts. Drug Dev Ind Pharm 2011;37:1200-7.

13. Kulkarni AS, Aloorkar NH, Mane MS, Gaja JB. Liquisolid systems: A review. Int J Pharm Sci Nanotechnol 2010;3:795-802.

14. Lakshmi MS, Kumara PS, Kumar TR. A novel approach for improvement of solubility and bioavailability of poorly soluble drugs: Liquisolid compact technique. Int J Res Pharm Biomed Sci 2012:3:1621-32.

15. Singh SK, Prakash D, Srinivasan KK, Gowthamarajan K. Liquisolid compacts of glimepiride: An approach to enhance the dissolution of poorly water soluble drugs. J Pharm Res 2011;4:2263-8.

16. Spireas S, Sadu S. Enhancement of prednisolone dissolution properties using liquisolid compacts. Int J Pharm 1998;166:177-88.

17. Jatav RK. Formulation development and evaluation of controlled release tablets of famotidine. Int J Pharm Biol Arch 2012;3:858-66. 
18. US Pharmacopoeial Convention. USP 25 and NF 20; US Pharmacopoeia 25 and National formulary 20. Rockville, MD: US Pharmacopoeial Convention; 2002. p. 1388

19. Jain H, Ty P, Cs B, Bhandari A. Formulation and characterization of liquisolid tablets of valsartan for improvement of dissolution rate. Asian J Pharm Clin Res 2014;7:21-6.
20. Sruthi RS, Kaparthi S, Babu PR, Subrahmanyam CV. Formulation and in-vitro evaluation of efavirenz liquisolid compacts. Int J Pharm Pharm Res 2016;8:137-43.

21. Hussain MA, Gorre M, Rao R, Anjum M. Preparation and evaluation of nilvadipne liquisolid compacts. J Pharm Pharm Sci 2014;6:1-8. 